\title{
Small understorey trees have greater capacity than canopy trees to adjust hydraulic traits following prolonged drought in a tropical forest
}

André Giles ${ }^{1}$, Lucy Rowland ${ }^{2}$, Paulo Bittencourt ${ }^{3}$, David Bartholomew ${ }^{4}$, Sarah Coughlin ${ }^{5}$, Patrícia de Britto Costa ${ }^{3}$, Tomas Domingues ${ }^{6}$, Raquel Miatto ${ }^{7}$, Fernanda Barros ${ }^{3}$, Leandro Ferreira $^{8}$, Peter Groenendijk ${ }^{3}$, Alex Oliveira ${ }^{8}$, Antonio da Costa ${ }^{9}$, Patrick Meir ${ }^{10}$, Maurizio Mencuccini $^{11}$, and Rafael Oliveira ${ }^{3}$

${ }^{1}$ University of Campinas Institute of Biology

${ }^{2}$ University of Exeter

${ }^{3}$ University of Campinas

${ }^{4}$ University of Exeter College of Life and Environmental Studies

${ }^{5}$ University of Sao Paulo

${ }^{6}$ University of São Paulo

${ }^{7}$ Universidade de São Paulo

${ }^{8}$ Museu Paraense Emílio Goeldi

${ }^{9}$ Universidade Federal do Pará

${ }^{10}$ The Australian National University

${ }^{11}$ University of Edinburgh

October 9, 2020

\begin{abstract}
The future of tropical forests is dependent on the capacity of young trees to adjust to drought. We evaluated multiple hydraulic traits indicative of the drought tolerance of small trees across nine common genera at the world's longest-running tropical throughfall exclusion experiment and compared their responses with surviving large canopy trees. Small understorey trees increased specific hydraulic conductivity by $56.3 \%$ and leaf:sapwood area ratio by $45.6 \%$ in response to the drought treatment. However, understorey trees in both a control and the throughfall exclusion treatment had significantly lower minimum stomatal conductance and maximum hydraulic leaf-specific conductivity relative to the large trees, as well as significantly greater hydraulic safety margin (HSM) and PLC and embolism resitance, occupying a distinctly different hydrualic niche. The greater HSM of small understorey trees relative to large canopy trees likely enables them to adjust other aspects of their hydraulic systems to take advantage of increases in light availability in the understorey, driven by drought-induced mortality of canopy trees. Our results suggest that small understorey trees can adjust their hydraulic systems in response to changes in water and light availability and this has major implications for the regeneration potential of tropical forests following droughts.
\end{abstract}

\section{Hosted file}

Main_document.pdf available at https://authorea.com/users/365834/articles/485817-smallunderstorey-trees-have-greater-capacity-than-canopy-trees-to-adjust-hydraulic-traitsfollowing-prolonged-drought-in-a-tropical-forest 